\title{
Encefalite a Citomegalovírus em Doente com Vírus da Imunodeficiência Humana Negativa
}

\author{
Cytomegalovirus Encephalitis in an HIV-Negative Patient
}

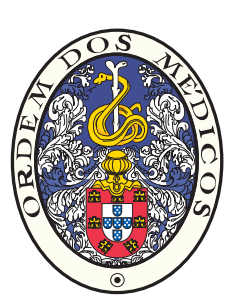

\author{
Carla Ferreira SANTOS ${ }^{1}$, Marlene DELGADO ${ }^{1}$, Ana Bárbara SIMÕES ${ }^{2}$, Joana NUNES ${ }^{3}$, Isabel PEREIRA ${ }^{4}$, Orlando \\ GASPAR ${ }^{1}$ \\ Acta Med Port 2013 Sep-Oct;26(5):608-613
}

\section{RESUMO}

As imunodeficiências secundárias encontram-se associadas a elevada incidência de infecções e neoplasias, bem como ao desenvolvimento de doenças auto-imunes. O status imunológico pode ser alterado por diversas condições, tais como a idade avançada, a malnutrição e as infecções micobacterianas. Contudo, o tratamento da condição primária resulta frequentemente na melhoria do compromisso imunológico. Os autores apresentam um caso de encefalite e hepatite por citomegalovírus, decorrente de reactivação viríca associada ao desenvolvimento de imunodeficiência secundária em doente Vírus da Imunodeficiência Humana negativa.

Palavras-chave: Citomegalovírus; Encefalite Viral; Infecções por Citomegalovírus.

\section{ABSTRACT}

Secondary immunodeficiences are associated with an increased incidence of infection and malignancy, as well with development of autoimmune disease. Immune system function is altered by many conditions, such as aging, malnutrition and mycobacterial infections. However, the treatment of the primary condition often results in the improvement of the immune compromise. The authors present a case of cytomegalovirus encephalitis and hepatitis, due to viral reactivation associated with development of secondary immunodeficience in an HIV-negative patient.

Keywords: Cytomegalovirus; Cytomegalovirus Infections; Encephalitis Viral.

\section{INTRODUÇÃO}

As Imunodeficiências secundárias, tal como as primárias, encontram-se associadas a elevada incidência de infecções e neoplasias, bem como ao desenvolvimento de doenças auto-imunes. ${ }^{1}$ Podem decorrer de diversas condições, entre as quais a infecção pelo VIH e terapias imunossupressoras, mas também devido a malnutrição, entre outras (Tabela 1). ${ }^{1}$ Verificam-se anomalias quer da imunidade inata quer da adaptativa, com manifestações clínicas muito diversas e por vezes subtis. ${ }^{2} \mathrm{O}$ tratamento da condição primária resulta frequentemente na melhoria do compromisso imunológico.

Talvez a causa mais bem conhecida de imunodeficiência secundária seja a infecção pelo $\mathrm{VIH}$, contudo a causa mais prevalente no mundo é a malnutrição, ${ }^{2}$ a qual se encontra associada na maioria dos estudos a um amplo espectro de defeitos imunes, alguns dos quais porventura ainda desconhecidos (Tabela 2), secundários a alterações da homeostasia bioquímica.

Por outro lado, a reactivação de infecções por micobactérias associa-se de forma característica ao declínio da imunidade com o envelhecimento. Em Portugal, de acordo com relatório da OMS que inclui dados até 2006, acima dos 60 anos são notificados 25 casos de tuberculose / 100000 habitantes, sendo $4 / 5$ do sexo masculino. Nas infecções micobacterianas, ocorre diminuição da capacidade dos fagócitos mononucleados de matar o invasor (factor perpetuador de infecção) e de sinalizar activação celular, o que condiciona o risco aumentado de infecção secundária perante um caso de tuberculose, particularmente na sua forma miliar. ${ }^{1}$

Relativamente às formas de tuberculose extra-pulmonar, o envolvimento ganglionar é o mais comum contribuindo com cerca de $40 \%$ dos casos e nestes mais de $40 \%$ apresentam ainda envolvimento pulmonar associado, ${ }^{3}$ já a forma miliar é bastante menos frequente. Todavia, a proporção de ambas as formas está aumentada nos casos de imunodeficiência.

Na população mundial, a sero-prevalência do citomegalovírus (CMV) varia entre 40 e $100 \% .^{4-6} \mathrm{~A}$ doença severa por CMV geralmente nos doentes imunocompetentes decorre de infecção primária, enquanto nos imunocomprometidos é secundária à reactivação. A infecção por $\mathrm{CMV}$ pode em menos de $1 \%$ de todos os casos induzir síndromes neurológicos, ${ }^{4,6}$ tais como encefalite, a qual é relativamente mais frequente nos indivíduos imunocomprometidos. De uma forma geral, a encefalite por CMV é rara e de muito difícil diagnóstico, o qual se deve basear na apresentação clínica, resultados de imagem e marcadores virológicos, sobretudo da PCR (polimerase chain reaction) do ADN do CMV no LCR. ${ }^{7}$ Esta correlaciona-se com doença activa e não com infecção latente. ${ }^{8}$

O tratamento deve ser instituído aquando da suspeita

1. Serviço de Medicina Interna 2. Hospital de São Teotónio. Viseu. Portugal.

2. Serviço de Medicina Geral e Familiar. Hospital de São Teotónio. Viseu. Portugal.

3. Serviço de Neurologia. Hospital de São Teotónio. Viseu. Portugal.

4. Serviço de Pneumologia. Hospital de São Teotónio. Viseu. Portugal.

Recebido: 25 de Março de 2009 - Aceite: 16 de Abril de 2009 | Copyright @ Ordem dos Médicos 2013 
Tabela 1 - Condições associadas a imunodeficiência secundária.

\section{Tratamento Imunossupressor}

Quimioterapia; Terapia de doenças auto-imunes; Ablação medular pré-transplante;

Tratamento/Profilaxia Doença do Enxerto vs Hospedeiro

Tratamento de rejeição de órgão sólido após trasnplante

\section{Infecção}

Infecção viríca; VIH, SIDA; Sarampo; Infecção bacteriana (superantigénios);

Infecção micobacteriana, Infestação parasitária

\section{Neoplasia}

Doença de Hodgkin; Leucemia linfocítica crónica, Mieloma múltiplo; Tumores sólidos

\section{Alterações da Homeostasia Bioquímica}

Diabetes mellitus; Insuficiência renal/Diálise; Insuficiência hepática/Cirrose; Malnutrição

\section{Doenças Auto-Imunes}

Lúpus eritematoso sistémico; Artrite reumatóide

\section{Trauma}

Queimaduras

\section{Exposição Ambiental}

Radiação ionizante; Radiação ultra-violeta; Químicos tóxicos

\section{Outros}

Gravidez; Stress; Asplenia/hiposplenismo; Transfusão sanguínea alogénica; Idade

Tabela 2 - Defeitos imunes associados a condições de imunodeficiência secundária.

\section{Malnutrição}

Anergia cutânea

Diminuição da resposta mitogénica dos linfócitos T

Diminuição dos linfócitos T circulantes

Aumento relativo das células natural killer

Diminuição da capacidade fagocítica

Prejuízo da resposta humoral (as imunoglobulinas séricas podem estar aumentadas, normais ou diminuídas) Hipocelularidade relativa nos órgãos linfóides

Escassez de folículos linfóides

\section{Idade}

Anergia cutânea

Diminuição da capacidade fagocítica

Diminuição da quimiotaxia

Diminuição dos linfócitos T circulantes

Supra-regulação do termóstato hipotalâmico

Títulos baixos de anticorpos específicos 
da infecção por CMV e consiste em Ganciclovir, Foscarnet (no caso de resistência ao Ganciclovir) ou a associação de ambos (sobretudo nos casos de SIDA).

Os autores apresentam o caso clínico de uma doente idosa, que desenvolve um quadro de encefalite e hepatite a CMV por reactivação vírica na sequência de um estado de malnutrição com poucos meses de evolução e de tuberculose ganglionar e miliar.

\section{CASO CLÍNICO}

Doente de 74 anos, do sexo feminino, que vive sozinha e sem antecedentes patológicos relevantes. É referenciada ao Serviço de Urgência por quadro com cerca de um mês de evolução composto por febre, surtos psicóticos transitórios e défices cognitivos (perturbação mnésica e défice de nomeação), astenia, anorexia, perda ponderal significativa mas não quantificada e dispneia de esforço mais recentemente.

À entrada apresenta-se confusa, desorientada no espaço e no tempo, com lentificação psicomotora, diminuição da fluência e défice de nomeação, emagrecida com Índice de Massa Corporal $=19,5 \mathrm{Kg} / \mathrm{m}^{2}$ e pregas cutâneas não preenchidas, pele e mucosas ligeiramente pálidas, normotensa, febril (temperatura axilar de $38.6^{\circ} \mathrm{C}$ ), eupneica em repouso, com murmúrio vesicular rude bilateralmente à auscultação pulmonar. Analiticamente verifica-se leucopenia (3.900 x $\left.10^{9} / \mathrm{L}\right)$ com linfocitopenia $\left(800 \times 10^{9} / \mathrm{L}\right)$, anemia normocrómica $(11.1 \mathrm{~g} / \mathrm{dL})$, hiponatrémia $(132 \mathrm{mEq} / \mathrm{L})$ e elevação de DDímeros (2280ng/mL), TGO (44UI/L), LDH (757 UI/L) e PCR (9.77 mg/dL). A Radiografia torácica revela padrão reticulo-micronodular difuso (Fig. 1) e a Tomografia computorizada crânio-encefálica (TC-CE) revela discreto alargamento atrófico das vias do LCR (Fig. 2).

A doente é internada para estudo instituindo-se isolamento respiratório. O estudo analítico inicial revela VS

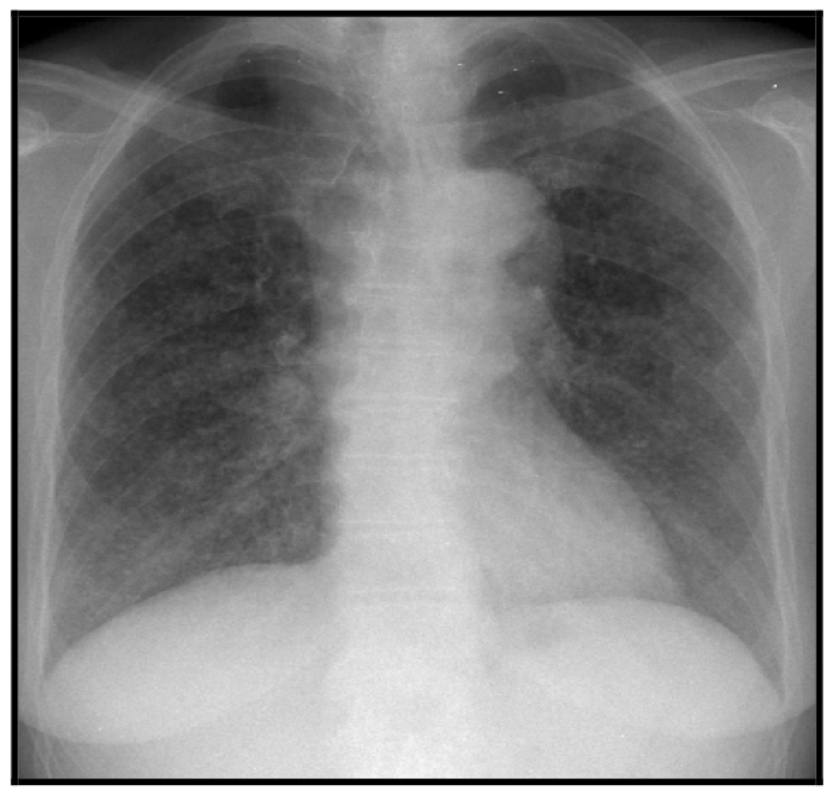

Figura 1 - Rx Tórax - Padrão reticulo-micronodular difuso e bilateral.
$35 \mathrm{~mm} / 1^{\mathrm{a} h}$, ADA 73,2UI/L, SACE 65UI/L, TGP 215UI/L, TGO 218UI/L, imunofenotipagem linfocitária com contagens de $\mathrm{CD}_{3}\left(581 / \mathrm{mm}^{3}\right), \mathrm{CD}_{4}\left(458 / \mathrm{mm}^{3}\right)$ e $\mathrm{CD}_{8}\left(87 / \mathrm{mm}^{3}\right)$ diminuídas e elevação do ratio $\mathrm{CD}_{4} / \mathrm{CD}_{8}(4,8)$. O proteinograma electroforético apresenta hipoalbuminémia de 2,5g/ $\mathrm{dL}$. As hemoculturas e urocultura, incluindo em meio de Lowenstein, resultam negativas. As serologias para Vírus da hepatite B e C, vírus Herpes simplex (VHS) tipo 1 e 2 e Treponema pallidum, bem como reacção de Widal, Wrigth e Weil-Felix são negativas.

Ao sétimo dia de internamento (D7) verifica-se positividade da prova de Mantoux e observam-se bacilos acido-alcool resistentes (BAAR) nas amostras de suco gástrico. Admite-se Tuberculose miliar e inicia terapia antibacilar quádrupla com Isoniazida, Rifampicina, Pirazinamida e Etambutol. A Tomografia computorizada (TC) toraco-abdomino-pélvica (Fig. 3), realizada ao D8, evidencia padrão micronodular difuso e bilateral do parênquima pulmonar (padrão miliar), várias adenopatias mediastínicas e para-aórticas e massa peri-pancreática. Para esclarecimento da natureza da massa, efectua-se punção aspirativa mediante eco-endoscopia digestiva alta, cuja amostra revela tratar-se de material necro-inflamatório, sem granulomas ou células de Langhans; porém desenvolvem-se BAAR. Admite-se então tuberculose ganglionar.

Após a introdução dos antibacilares, ocorre evolução favorável do quadro clínico com apirexia precoce, remissão progressiva da síndrome constitucional bem como do estado bacilífero às três semanas de tratamento e, aos dois meses, resolução radiológica das alterações pulmonares (Fig. 4). Esta resposta é consonante com o facto da espécie identificada, Mycobacterium tuberculosis complex, mediante sonda de ADN, ser sensível aos quatro antibacilares de primeira linha instituídos (Bactec).

No que diz respeito ao quadro neurológico, no D1 é

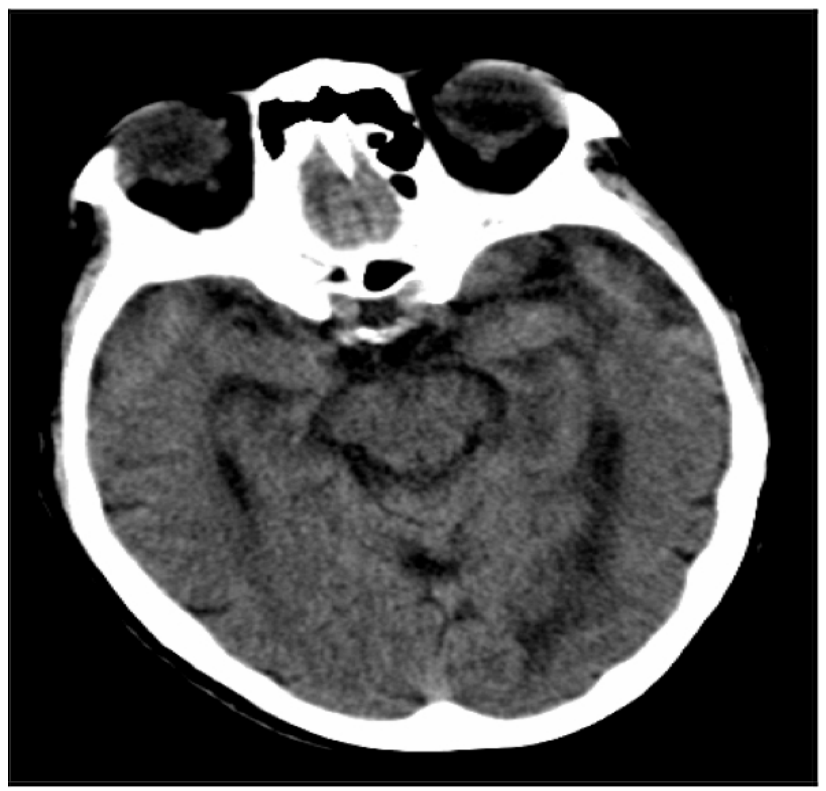

Figura 2 - TC CE - Discreto alargamento atrófico das vias do LCR. 
realizada Punção lombar cujo estudo inicial revela raros leucócitos, normoproteinorráquia e normoglicorráquia. Ao D3 realiza Electroencefalograma (EEG) (Fig. 5) que revela alteração cerebral difusa de tipo metabólico e a Ressonância Magnética crânio-encefálica (RNM CE) não traz informação adicional relevante (Fig. 6).

Entretanto, o Ziehl Neelsen e as culturas do LCR resultam negativos bem como a pesquisa de BAAR e VHS 1 e 2 mediante PCR. Um mês após a realização da punção
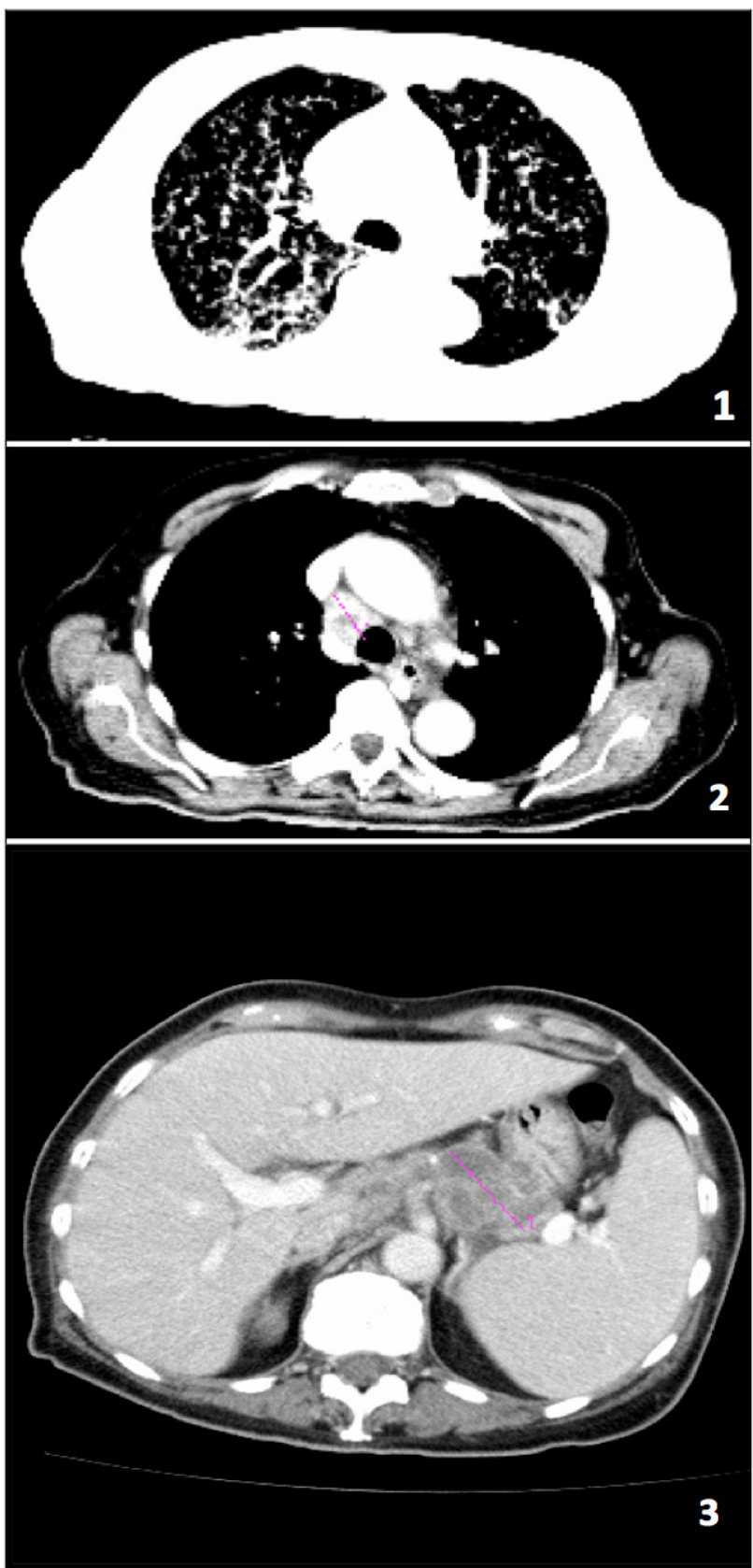

Figura 3 - TC Toraco-Abdomino-Pélvica - Padrão micronodular difuso do parênquima pulmonar desde os vértices até às bases (1). Nas bases observam-se ainda algumas áreas em vidro despolido. Várias adenopatias mediastínicas, com dimensões até $24 \mathrm{~mm}$ de diâmetro (2). Massa com $4.7 \mathrm{~cm}$, adjacente ao tronco celíaco e acima do corpo pancreático - Conglomerado adenopático? Tumor pancreático? (3) Adenopatias para-aórticas e intercavo-aórticas. lombar, obtém-se o resultado de identificação de CMV por PCR de ADN no LCR. No entanto, a doente apresenta serologia compatível com infecção vírica antiga, sendo a pesquisa por PCR de ADN de CMV sérica negativa. Admite-se Encefalite a CMV por reactivação vírica e inicia Ganciclovir, na dose de $5 \mathrm{mg} / \mathrm{Kg}$ de 12/12 horas que manteve durante 21 dias, passando depois a terapêutica de manutenção. Após cinco semanas de Ganciclovir ainda se identifica o CMV no LCR e só aos dois meses é que a pesquisa resulta negativa, com descontinuação da terapia anti-vírica. Concomitantemente, ocorre remissão parcial do quadro neurológico, mantendo discretos défices mnésicos, acompanhados de normalização das alterações electroencefalográficas e da função hepática.

Aos dois meses repete serologia para o $\mathrm{VIH} 1$ e 2 que se mantém negativa e verifica-se normalização do leucograma e da imunofenotipagem linfocitária.

Durante o internamento é feita optimização do estado nutricional da doente.

A doente tem alta para o domicílio ao D105.

\section{DISCUSSÃO}

A idade avançada, a malnutrição e a tuberculose são três condições que se encontram frequentemente em concomitância.

A tuberculose miliar, decorrente de infecção primária ou de reactivação de focos antigos disseminados aquando de imunodepressão, ${ }^{3,9}$ geralmente manifesta-se de forma inespecífica cingindo-se a clínica, tal como no caso descrito, a um síndrome constitucional. Como tal, é necessário um elevado grau de suspeição para o seu diagnóstico, ${ }^{3}$ o qual é por vezes facilitado, pela ocorrência de dispneia e/ou pela evidência imagiológica, mediante radiologia conven-

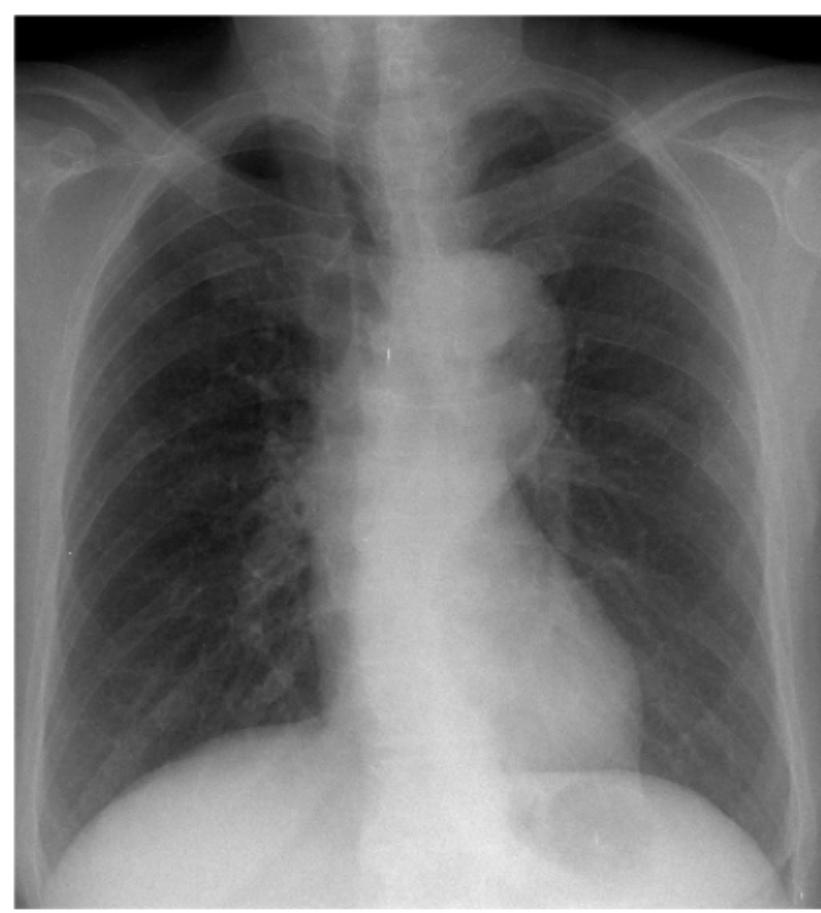

Figura 4 - Rx Tórax - Resolução do padrão reticulo-micronodular. 


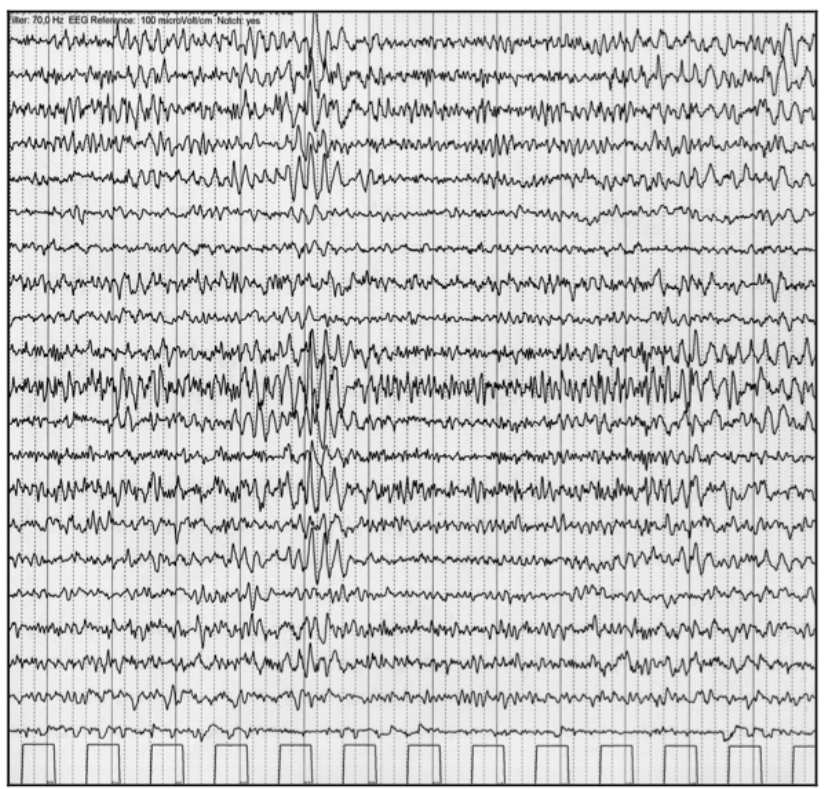

Figura 5 - Electroencefalograma - Existência de anomalias lentas intermitentes conferindo ao exame um aspecto oscilante, com preservação dos ritmos posteriores de base, características que apontam para uma alteração cerebral difusa de tipo metabólico. Não se registam complexos periódicos.

cional ou TC torácica, de um padrão reticulonodular difuso composto por nódulos com 1 até $3 \mathrm{~mm}$ de diâmetro. Por outro lado, o Zielh-Nielsen ${ }^{3}$ da expectoração e a prova de Mantoux ${ }^{10}$ são negativos em $80 \%$ e mais de $50 \%$ dos casos de tuberculose miliar, ${ }^{3}$ respectivamente.

Apesar da clínica inicial do caso descrito ser inespecífica, a doente desenvolve dispneia e a Radiografia torácica revela padrão reticulo-micronodular, pelo que se suspeita de tuberculose miliar e procede-se ao isolamento respiratório. O diagnóstico foi reforçado pela positividade da prova de Mantoux e confirmado pela observação de BAAR no suco gástrico. Verifica-se ainda algumas alterações analíticas enquadradas na entidade nosológica, quer hematológicas - anemia normocítica e leucopenia com linfocitopenia, ${ }^{3}$ quer bioquímicas - elevação de VS e hiponatrémia.

Perante uma situação de disseminação bacilar hematogénica numa doente com quadro neurológico tornou-se imperioso a exclusão de envolvimento do SNC pela tuberculose. Por outro lado, a hipótese de tumor pancreático levantada pela TC obriga à realização de biópsia, dada a possibilidade de imunodeficiência secundária no contexto de tumor sólido, favorecedora da infecção por BAAR.

No que diz respeito às formas de tuberculose ganglionar, os locais mais frequentemente envolvidos são os gânglios cervicais posteriores e supra-claviculares, contudo neste caso o isolamento de BAAR verifica-se a partir de biópsia do conglomerado adenopático abdominal. A ausência de células de Langhans ou de granulomas caseosos é explicada pela depressão da imunidade celular.

A posteriori, favorecido pela idade, e secundariamente à malnutrição e infecção micobacteriana, verifica-se imuno-

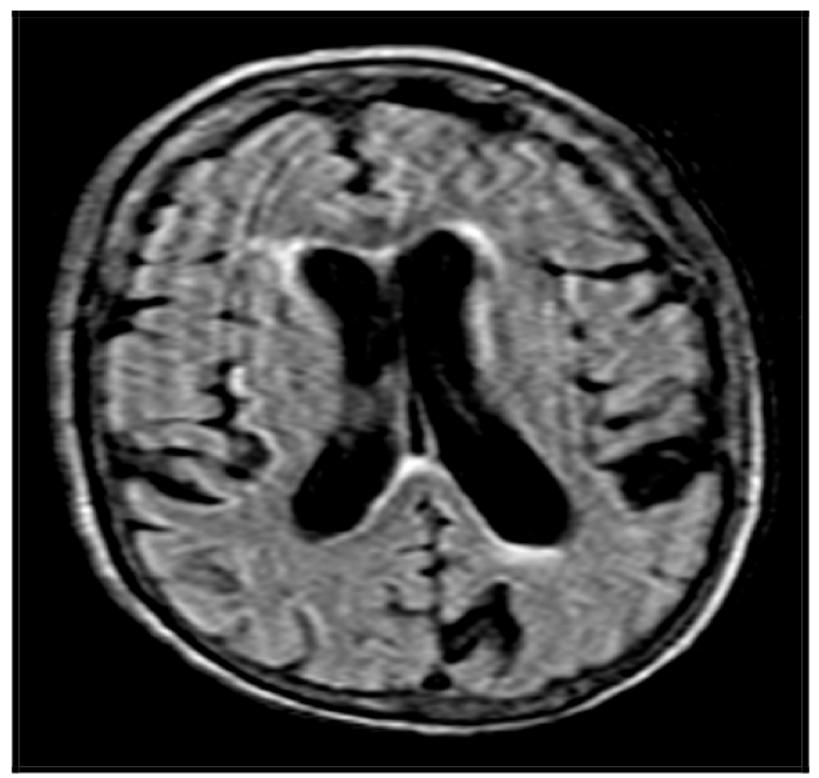

Figura 6 - RNM CE - Hipersinal peri-ventricular em FLAIR que poderá reflectir leucoencefalopatia isquémica discreta. Alargamento atrófico global das vias do líquor.

depressão com reactivação de CMV, que tal como outros membros da família Herpesviridae tem capacidade de estabelecer infecção latente após resolução de infecção aguda.

A encefalite a CMV apresenta clínica diversa, sendo muito fruste no caso descrito, evolução subaguda ao longo de semanas sobretudo nos doentes com periventriculite, ${ }^{6}$ exame cito-químico do LCR inespecífico e exames de imagem com baixas sensibilidade e especificidade. A RNM CE é mais sensivel que a TC na detecção de alterações relacionadas com a encefalite a CMV, podendo sugerir ou diagnosticar ventriculite (hiper-sinal na superfície epidendimária dos ventrículos) em aproximadamente $45 \%$ e $30 \%$ dos casos, respectivamente. ${ }^{6}$

Com uma sensibilidade e uma especificidade na detecção de ADN de CMV no LCR superiores a $80 \%$ e $90 \%$, respectivamente, a PCR tem indicação (recomendação grau 1) para ser realizada sempre no diagnóstico de infecção do SNC por CMV. ${ }^{5}$ A quantificação do ADN por PCR é importante na monitorização da resposta à terapêutica. Por outro lado, a deteç̧ão de viremia de CMV por PCR, que no nosso caso foi negativa, está associada a elevado risco de desenvolvimento de retinite em doentes com envolvimento do SNC. Apesar da encefalite a CMV ter pior prognóstico no idoso, ${ }^{5}$ verificou-se evolução favorável com Ganciclovir. Na reactivação de infecção por CMV a hepatite encontra-se predominantemente associada a casos sintomáticos de infecção do SNC.

Com o tratamento das infecções vírica e micobacteriana, acompanhado de optimização do estado nutricional, verificou-se melhoria do status imunológico reflectido pela normalização da imunofentipagem linfocitária. Este caso salienta-se sobretudo pela sua complexidade e pelo facto de se ter detectado uma infecção do SNC a CMV numa doente sem infecção por VIH. 


\section{CONCLUSÕES}

Os autores concluem que perante uma situação de malnutrição e tuberculose, particularmente nas suas formas miliar e ganglionar, se desenvolveu um estado de imunodeficiência secundária com prejuízo da imunidade celular o que predispôs à reactivação do vírus $\mathrm{CMV}$ com encefalite $\mathrm{e}$ hepatite.

Alertam para o facto das condições associadas a imunodeficiências secundárias ocorrerem de forma frequente na prática clínica diária, particularmente nas faixas etárias mais avançadas, pelo que muitos dos doentes tidos como imunocompetentes apresentam compromisso imunológico de grau variável.

\section{REFERÊNCIAS}

1. Bonilla FA, Stiehm R, Feldweg AM. Secondary immune deficiency due to miscellaneous causes. Up to date Chinen J, Shearer WT: Secondary immunodeficiencies, including HIV infection. J Allergy Clin Immunol. 2008;121:S388-92.

2. Raviglione MC, O’Brien RJ. Mycobacterial Diseases. In: Fauci AS, Braunwald E, Kasper DL, Hauser SL, Longo DL, Jameson JL, editors. Harrison's Principles of Internal Medicine. $17^{\text {th }}$ ed. New York: Mc Graw Hill; 2008. Part seven: Infectious disease:Section 8.

3. Ben Abdelhafidh N, Battikh R, Laabidi J, M'sadek F, Ajili F, Ben Moussa $\mathrm{M}$, et al. Cytomegalovirus myelitis in immunocompetent adult. Rev Med Interne. 2006;27:883-5.

4. Rafailidis PI, Mourtzoukou EG, Varbobitis IC, Falagas ME. Severe cytomegalovirus infection in apparently immunocompetent patients: a sys-
As condições supracitadas devem ser individualmente identificadas e optimizadas de forma a prevenir as diversas consequências, quer infecciosas, neoplásicas ou auto-imunes, que podem ser eventualmente fatais.

\section{CONFLITO DE INTERESSES}

Os autores declaram não existir qualquer conflito de interesses relativamente ao presente artigo.

\section{FONTES DE FINANCIAMENTO}

Não existiram fontes externas de financiamento para a realização deste artigo.

tematic review. Virol J. 2008;5:47

5. Griffiths P. Cytomegalovirus Infection of the Central Nervous System. Herpes. 2004;11:95A-104A

6. Ropper AH, Browmn RH. Adams and Victor's. Principles of Neurology. Major Categories of Neurologic Disease. New York: Mc Graw Hill; 2005.

7. Studahl M, Bergström T, Ekeland-Sjöberg K, Ricksten A. Detection of cytomegalovirus DNA in cerebrospinal fluid in immunocompetent patients as a sign of active infection. J Med Virol. 1995;46:274-80.

8. Fanning A. Tuberculosis: 6. Extrapulmonary disease. CMAJ. 1999;160:1597-603.

9. Golden MP, Vikram HR. Extrapulmonary tuberculosis: an overview. Am Fam Physician. 2005;72:1761-8. 